\title{
Delayed Local Recurrence Following Radiation Therapy for Muscle-Invasive Bladder Cancer Emphasizing the Need for Lifelong Surveillance: a Case Report
}

\author{
Rajitha Sunkara, Rajinikanth Ayyathurai, Alan Nieder, \\ and Murugesan Manoharan* \\ Department of Urology, University of Miami Miller School of Medicine, Miami, FL \\ E-mail: $\underline{\text { mmanoharan@med.miami.edu }}$
}

Received November 19, 2007; Revised January 13, 2008; Accepted January 19, 2008; Published February 19, 2008

We report a case of a 68-year-old gentleman who developed a delayed local recurrence 30 years following curative radiation treatment for muscle-invasive bladder cancer. This case emphasizes the importance of lifelong post-treatment surveillance for bladder cancer.

KEYWORDS: bladder cancer, delayed local recurrence, surveillance, muscle invasive

\section{INTRODUCTION}

Bladder cancer is the fourth most common malignancy in men in the U.S. In particular, muscle-invasive bladder cancer has a high mortality rate[1].The objective of this case is to emphasize the need for lifelong surveillance for bladder cancer.

\section{CASE REPORT}

A 68-year-old gentleman presented with a 6-week history of dysuria and hematuria. He was neither a smoker nor had any occupational exposure for bladder cancer. Thirty years ago (1978), the patient was diagnosed with stage T1, high-grade, urothelial cancer of the bladder. Initially, he was treated with intravesical BCG. Three years later, he developed tumor recurrence. Subsequent transurethral resection of the bladder tumor revealed muscle-invasive cancer.

In 1981, he was treated with external beam radiation therapy (EBRT) at Memorial Sloan Kettering Cancer Center, New York. The treatment schedule and precise dosage of the radiation therapy is not available. He was initially followed with cytology and cystoscopy every 6 months during the first 5 years, and subsequently with yearly cystoscopy and cytology for the last 25 years. No disease recurrence was noted.

The most recent cystoscopy performed in March 2007 demonstrated a 3-cm nodular lesion at the trigone. He underwent a transurethral resection of the lesion. The pathology demonstrated a high-grade, 
muscle-invasive, urothelial cancer. Subsequently, the patient was referred to us for further management. His metastatic workup with CT scan of the abdomen and pelvis and bone scan were negative.

The patient underwent a cystoprostatectomy with ileal conduit creation in April 2007. The pathology revealed a 2.5-cm, infiltrating, high-grade, urothelial carcinoma extending into the perivesical adipose tissue (pT3a) .There was no evidence of perineural or lymphovascular invasion and the margins were negative. Extensive mucosal ulceration with stromal reactive changes and transitional cell carcinoma in situ were also observed. His postoperative course was uneventful and he was discharged home on the $7^{\text {th }}$ postoperative day. He is currently receiving adjuvant chemotherapy with Cisplatin and Gemcitabine.

\section{COMMENTS}

Urothelial cancer is uncommon before the age of 40 and represents less than $4 \%$ of all bladder tumors[2]. In our case, this gentleman initially presented with muscle-invasive bladder cancer at a relatively young age of 38 years. The treatment of bladder cancer is based on the grade and stage of the tumor irrespective of the age of the patient[3]. The treatment modalities for muscle-invasive bladder cancer include cystectomy, EBRT, chemotherapy, and combined modality approaches[3].

Table 1

Local relapse-free rates for patients with T 2-T4 disease following radiation therapy.

\begin{tabular}{lcccc}
\hline Local relapse- free rate & $\begin{array}{r}\text { T2 } \\
(\%)\end{array}$ & $\begin{array}{c}\text { T3 } \\
(\%)\end{array}$ & $\begin{array}{c}\text { T4 } \\
(\%)\end{array}$ & $\begin{array}{c}\text { Overall } \\
(\%)\end{array}$ \\
\hline $5-\mathrm{yr}$ & 44.5 & 27 & 0 & 34 \\
\hline $10-\mathrm{yr}$ & 44.5 & 26 & 0 & 32 \\
\hline
\end{tabular}

This patient received curative radical EBRT, which is an accepted alternative for radical cystectomy[3]. The recurrence rate for muscle-invasive bladder cancer treated with radiotherapy at varying intervals is reported to be $43.6 \%$. (Table 1)[4]. Because the recurrent tumor is of the same histological type as the primary tumor, this is not a second malignancy from previous radiation therapy[5].

In the past, follow-up of patients with bladder cancer is usually 5-10 years[6].There is no definitive consensus on the duration of follow-up for the patients with bladder cancer treated with bladderconserving methods[7]. Recently, more and more urologists are favoring the idea of lifelong follow-up. The American Urological Association recommends post-treatment surveillance every 3-6 months, with cystoscopies for the initial 3 years and at least yearly later on.

We suggest that all patients with muscle-invasive bladder cancer who have undergone bladdersparing treatment should have urologic follow-up throughout their life. They should all be counseled about the importance and need of prolonged surveillance, and the risk of delayed local recurrence.

\section{ACKNOWLEDGMENT}

Financial support was received from “CURED 2007” and Mr. Vincent A. Rodriguez.

\section{REFERENCES}

1. Sherif, A., Jonsson, M.N., and Wiklund, N.P. (2007) Treatment of muscle-invasive bladder cancer. Expert Rev. Anticancer Ther. 7, 1279-1283. 
2. Blanchard, J.M., Graziana, J.P., Bonnal, J.L., Biserte, J., and Mauroy, B. (2003) Bladder tumor in young patients: a series of 26 cases. Comparison with a review of the literature. Prog. Urol. 13, 227-233.

3. Pos, F., Horenblas, S., Dom, P., et al. (2005) Organ preservation in invasive bladder cancer: brachytherapy, an alternative to cystectomy and combined modality treatment? Int. J. Radiat. Oncol. Biol. Phys. 61, 678-686.

4. $\quad$ Chahal, R., Sundaram, S.K., Iddenden, R., Forman, D.F., Weston, P.M., and Harrison, S.C. (2003) A study of the morbidity, mortality and long-term survival following radical cystectomy and radical radiotherapy in the treatment of invasive bladder cancer in Yorkshire. Eur. Urol. 43, 246-257.

5. Liauw, S.L., Sylvester, J.E., Morris, C.G., Blasko, J.C., and Grimm, P.D. (2006) Second malignancies after prostate brachytherapy: incidence of bladder and colorectal cancers in patients with 15 years of potential follow-up. Int. J. Radiat. Oncol. Biol. Phys. 66(3), 669-573.

6. Merseburger, A.S. and Kuczyk, M.A. (2007) The value of bladder-conserving strategies in muscle-invasive bladder carcinoma compared with radical surgery. Curr. Opin. Urol. 17, 358-362

7. Pollack, A., Zagars, G.K., and Swanson, D.A. (1994) Muscle-invasive bladder cancer treated with external beam radiotherapy: prognostic factors. Int. J. Radiat. Oncol. Biol. Phys. 30, 267-277.

\section{This article should be cited as follows:}

Sunkara, R., Ayyathurai, R., Nieder, A., and Manoharan, M. (2008) Delayed local recurrence following radiation therapy for muscle-invasive bladder cancer emphasizing the need for lifelong surveillance: a case report. TheScientificWorldJOURNAL: TSW Urology 8, 166-168. DOI 10.1100/tsw.2008.34. 


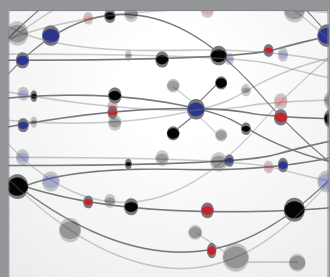

The Scientific World Journal
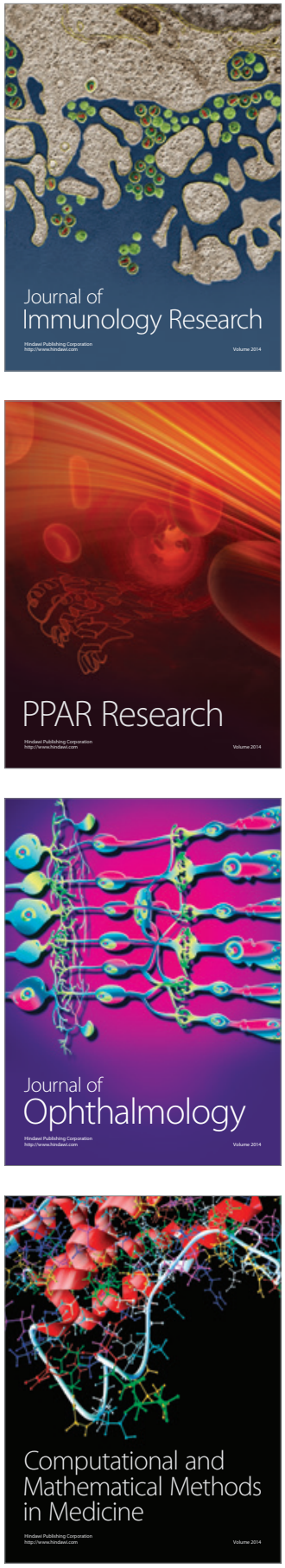

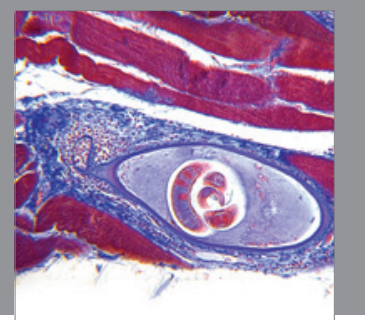

Gastroenterology

Research and Practice
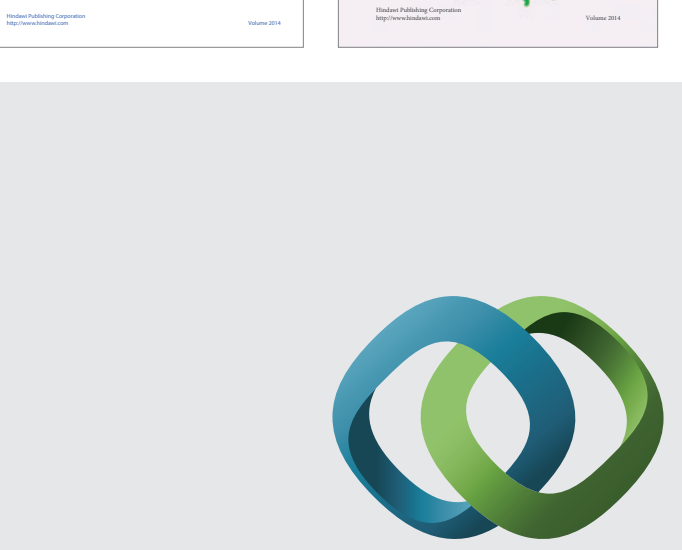

\section{Hindawi}

Submit your manuscripts at

http://www.hindawi.com
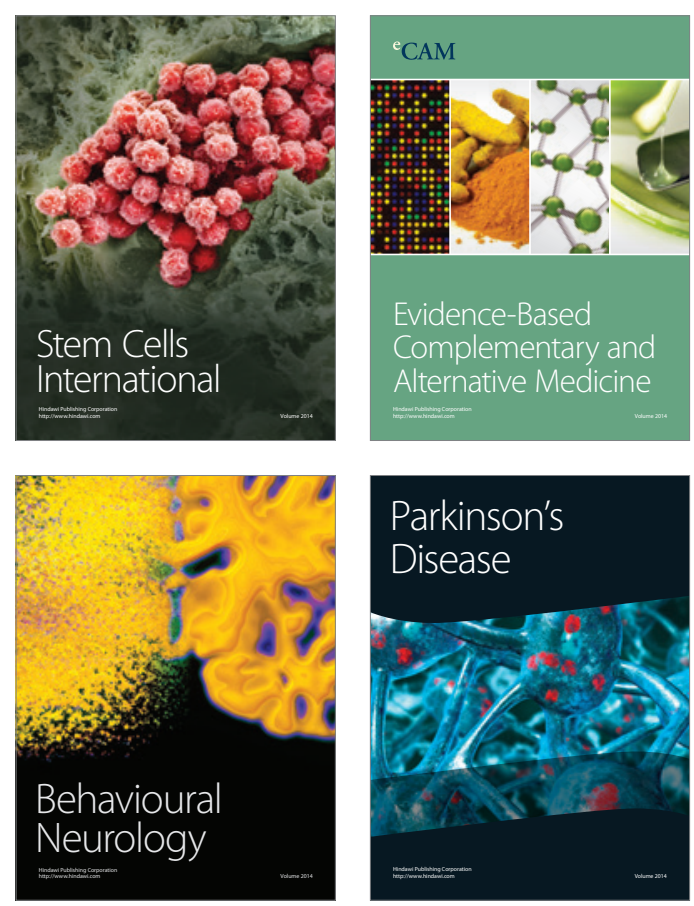

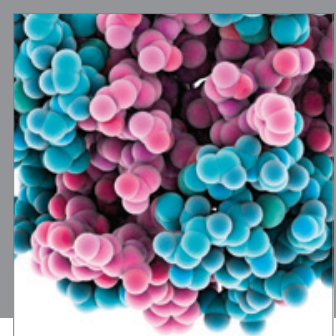

Journal of
Diabetes Research

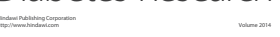

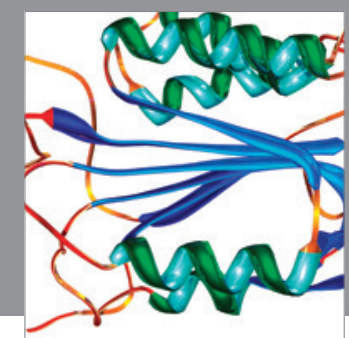

Disease Markers
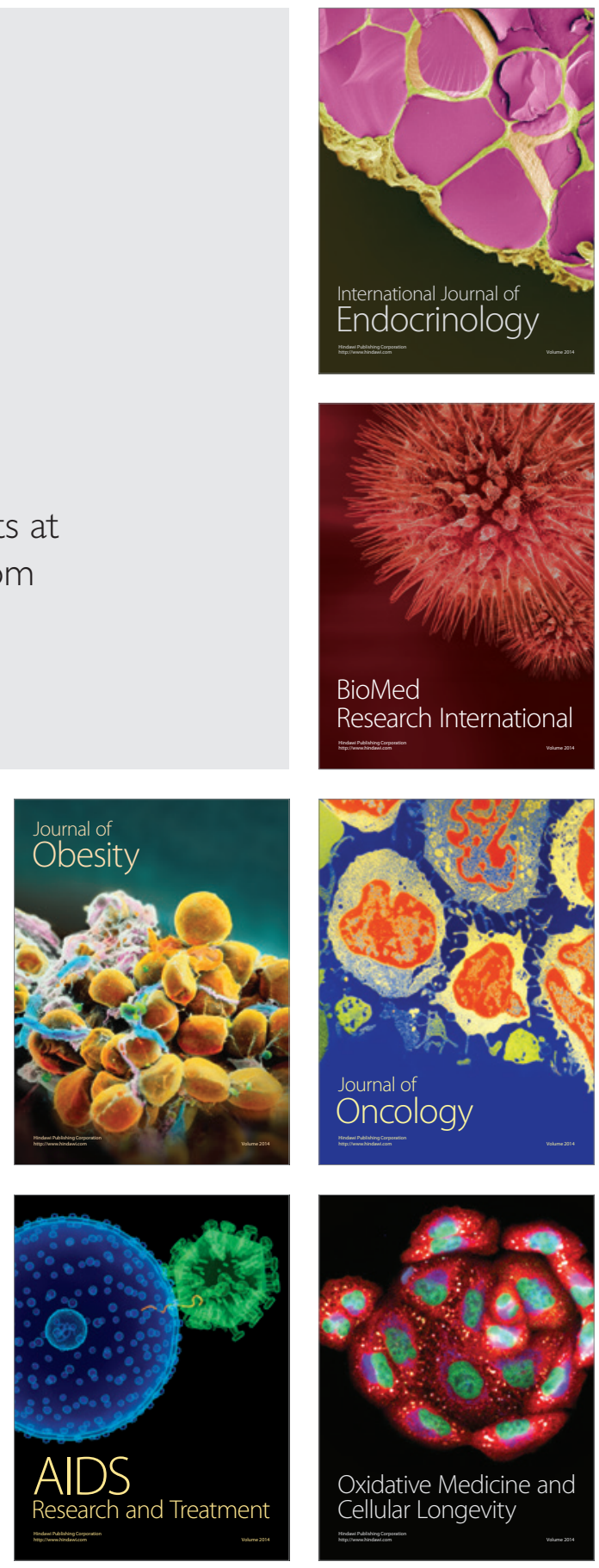